\title{
Indirect measures of learning transfer between real and virtual environments
}

\author{
Michael Garrett and Mark McMahon \\ Edith Cowan University, Australia
}

\begin{abstract}
This paper reports on research undertaken to determine the effectiveness of a 3D simulation environment used to train mining personnel in emergency evacuation procedures, designated the Fires in Underground Mines Evacuation Simulator (FUMES). Owing to the operational constraints of the mining facility, methods for measuring learning transfer were employed which did not require real world performance evaluation. Transfer measures that examined simulator performance relative to real world experience, fidelity assessment, and appraisal of the training value of the platform were utilised. Triangulation of results across all three measures indicated the presence of learning transfer, suggesting the viability of indirect measures in instances where real world performance testing is not possible. Furthermore, these indirect measures of learning transfer also provided some insight as to the strengths and weaknesses of the simulation design, which could be used to inform the development of future versions of the product.
\end{abstract}

\section{Introduction}

Computer-generated simulation environments can be utilised to provide 3D representations of real, recreated, abstract, or imaginary environments that may otherwise be of impractical size, infeasible distance, prohibitive cost, or too significant a hazard to experience in person (Baylis, 2000; Dalgarno \& Lee, 2010). As such, simulation environments can provide a safe and effective means for developing knowledge and skills for real world application by situating learning within an authentic representation of the activity, context and culture in which it is developed and used (Brown, Collins, \& Duguid, 1989; Jonassen, 2000; Keh, Chang, Lin, \& Hsu, 2005; Li, D'Souza, \& Du, 2011; Smith, 1988).

Recent innovations within the gaming industry have provided the technical impetus for developing 3D simulation environments, where rapid advancements in hardware and software technologies have been fuelled by high consumer demand. This has given rise to the serious games movement, which focuses on the application of gaming technologies and concepts for simulation and learning purposes. Threedimensional gaming technologies have been successfully used to this end in fields such as defence (Garrett \& McMahon, 2010), medicine (Depledget, Stone, \& Bird, 2011; Stone, 2011), mining (Tichon \& Burgess-Limerick, 2011), and architecture (Schroeder, 2011).

\section{Three-dimensional simulation environments}

Computer-generated 3D environments based on gaming technologies are able to simulate real world environments by providing users fluid control within a realistic $3 \mathrm{D}$ space. The high visual fidelity inherent in this type of environment affords the depiction of authentic virtual spaces where the behaviour of objects and their subsequent relationships with each other and the user can be represented appropriately, whilst also providing sensations of presence and immersion (Germanchis, Cartwright, \& Pettit, 2005; Petridis et al., 2012; Sadowski \& Stanney, 2002; Shiratuddin \& Thabet, 2002).

Given these affordances, 3D simulation environments based on gaming technologies are well suited to the representation of real world tasks that may involve movement and orientation, complex object manipulation, or decision making in 3D space (Graafland, Schraagen, \& Schijven, 2012; Munro, Breaux, Patrey, \& Sheldon, 2002). Furthermore, the scripting languages and other programmable constructs inherent in gaming technology provide the ability to structure and facilitate the instructional process in accordance with a suitable pedagogical framework, where instruction, assessment, and feedback can be provided in response to user interaction. 


\section{Learning transfer}

A simulation represents a real world system to foster the transfer of knowledge and to develop conclusions that provide insight into the behaviour of the real world system being represented (McHaney, 1991; Towne, 1995). This operates under the assumption that a faithful representation encourages knowledge transfer between the simulation environment and the real world system that is being modelled.

This assumption is consistent with Brown et al.'s (1989) theory of situated cognition, which asserts that knowledge is situated within the activity, context and culture in which it is developed and used. Such activity promotes cognition through the deliberate use of the social and physical context of the environment (Brown et al., 1989). Situated learning endeavours to construct contextual, real life, and highly interactive practice environments that can simulate real life situational learning, where the development of knowledge and the competence to perform well at an enterprise are manifestations of the active interplay between experience and ability (Dobson et al., 2001; Keh et al., 2005).

Evaluating learning transfer between simulated and real world environments remains a complicated process which is measured indirectly via the relationship between training and performance (Skinner et al., 2009). Such evaluation is commonly undertaken by looking for improvements in the performance of a real world task or procedure after initial training in a corresponding simulation environment (Gopher, 2012; Rose, Attree, Brooks, Parslow, \& Penn, 2000). However, such an approach is not suitable in situations where performance testing in the real world environment is not feasible, necessitating the adoption of more abstract approaches. Skinner et al. (2009), for example, identify evaluation metrics for learning transfer in relation to (a) measures of technical matches of environments, and (b) behavioural measures. Similarly, Kirkpatrick (1994), as cited in Merriam \& Leahy (2005), provides a model for determining the effectiveness of training programs according to (a) the learner's reaction, (b) the knowledge acquired, (c) changes in participant's behaviour as a result of training, and (d) improvements at the organisational level.

\section{About the study}

The Fires in Underground Mines Evacuation Simulator (FUMES) was developed as part of a broader $\mathrm{Ph}$.D. study which sought to determine how problem-solving knowledge and skills could be effectively transferred between virtual and real world environments. This encompassed an evaluation of the effectiveness of FUMES in terms of its ability to facilitate learning transfer using participants employed at a real world mine. FUMES provided a scale, 3D representation of a section of this mine where users were tasked with evacuating in response to a simulated underground fire emergency. This entailed reaching one of two possible refuge chambers within the virtual mine, which are self-contained steel structures that provide a safe haven for mining personnel during an emergency. Participants could freely move and orientate within the virtual mine and were provided with a self-rescuer (a portable gas mask / oxygen supply) to allow them to safely negotiate smoke filled areas. The virtual mining environment itself was configured to match the real world mine as closely as possible in terms of the layout of the mine shafts and positioning of key objects and visual cues in order to allow participants to use their existing knowledge of the real world mine to navigate effectively. In this way, participants could enact the evacuation procedure used in the real world mine to safely negotiate the smoke and evacuate to a refuge chamber within the virtual mine.

This task was situated within a problem-based learning pedagogy in order to promote the development of knowledge which could be used during a real world emergency. Participants undertook a series of three problem-solving instances which required them to resolve the problem of determining a safe path to refuge within the virtual mine whilst avoiding environmental hazards such as smoke and fire. However, the problem-solving instances became progressively more ill-structured, complex, and domain specific in terms of the severity of the environmental conditions within the virtual mine and the extent of information that was provided explicitly at the onset of each instance. 
Forty-two participants were selected from personnel working at the mining facility to participate in the study. All participants had completed on-site induction training, which provided a minimum level of understanding of the mining environment and its emergency evacuation procedures. The vast majority of participants identified themselves as individuals who felt comfortable and confident around computers, and most had previous experience with computer games.

These participants were separated into two groups comprising 21 existing employees, with at least six months of full-time experience at the real world mine (Experienced Participants), and 20 new employees, with little to no experience at the real world mine (Novice Participants). The staff member responsible for personnel training at the mine administered participants and observed their interaction within FUMES (Training Staff Member). The Training Staff Member was also available to help Novice Participants if they became severely disorientated or lost within the virtual mine. A layout diagram of the mine detailing the location of refuge chambers was also provided to Novice Participants.

The following data collection methods were employed during the study:

- Web-based questionnaires for all Experienced Participants and Novice Participants, undertaken immediately following interaction with FUMES;

- Detailed phone interviews with 4 Experienced Participants, 3 Novice Participants, and the Training Staff Member;

- Input logs, consisting of time stamped keystroke and mouse movements detailing the nature of participant interaction. This provided an exact record of all participant input which could be replayed through FUMES for later analysis, and;

- Performance measures recorded as database entries for all participants which measured participant effectiveness within FUMES.

Owing to the fact that the underground mining environment was in operation twenty-four hours a day and thus not suitable for performance testing, indirect methods for measuring transfer were utilised which did not require real world interaction. These methods for measuring transfer (Lathan, Tracey, M. M. Sebrechts, Clawson, \& Higgins, 2002), including the participants utilised for each method, are described in Table 1 as follows:

Table 1

Methods for measuring transfer from the $3 D$ simulation environment

\begin{tabular}{|c|c|c|}
\hline Method & Description & Data analysed \\
\hline $\begin{array}{l}\text { Inverse transfer of } \\
\text { training }\end{array}$ & $\begin{array}{l}\text { Experts at the operational task perform the } \\
\text { same tasks, without practice, in a simulator. A } \\
\text { positive result assumes that a suitable training } \\
\text { program exists for the simulator }\end{array}$ & $\begin{array}{l}\text { - Performance measures } \\
\text { - Input logs } \\
\text { - Training Staff Member } \\
\text { interview }\end{array}$ \\
\hline $\begin{array}{l}\text { Assessment of } \\
\text { fidelity }\end{array}$ & $\begin{array}{l}\text { Describes the physical similarity between the } \\
\text { simulator and the real-world environment, } \\
\text { equipment, interface, or facility }\end{array}$ & $\begin{array}{l}\text { - Experienced Participants } \\
\text { questionnaire and interview } \\
\text { - Training Staff Member } \\
\text { interview }\end{array}$ \\
\hline Operator opinion & $\begin{array}{l}\text { Operators, instructors, training specialists and } \\
\text { students are asked to give their opinions on the } \\
\text { perceived training value of a simulator, features } \\
\text { of the simulators, or probable impact of } \\
\text { simulator based training on subsequent real } \\
\text { world performance }\end{array}$ & $\begin{array}{l}\text { - Experienced Participants } \\
\text { questionnaire and interview } \\
\text { - Novice Participants } \\
\text { questionnaire and interview } \\
\text { - Training Staff Member } \\
\text { interview }\end{array}$ \\
\hline
\end{tabular}

Each of these methods for determining learning transfer was examined in relation to the data collected during the FUMES study and triangulated to provide a valid assessment of learning transfer from multiple perspectives. 


\section{Results and discussion}

\section{Inverse transfer of training}

Positive outcomes for participant performance within FUMES were identified for the purpose of measuring transfer using the inverse transfer of training method (see Table 1). These positive outcomes, provided by subject matter experts at the mine, were based on metrics used to evaluate how successfully personnel evacuated during a real world emergency, as detailed in Table 2.

Table 2

Positive outcomes for the evaluation of problem-solving task performance

\begin{tabular}{|c|c|}
\hline Positive outcome & Description \\
\hline Evacuate to refuge chamber & $\begin{array}{l}\text { Participant reaches either one of the refuge chambers in the virtual } \\
\text { mining environment through the application of emergency evacuation } \\
\text { procedures used in the real world mine }\end{array}$ \\
\hline Ideal route & $\begin{array}{l}\text { Participant evacuates to a refuge chamber using the ideal route for a } \\
\text { given problem-solving instance, emphasising the most efficient route } \\
\text { which bypasses fire and smoke where possible }\end{array}$ \\
\hline Ideal refuge chamber & $\begin{array}{l}\text { Participant evacuates to the ideal refuge chamber for a given problem- } \\
\text { solving instance. The ideal refuge chamber is that which can be reached } \\
\text { using the least amount of physical exertion and which bypasses fire and } \\
\text { smoke where possible }\end{array}$ \\
\hline Efficiency & $\begin{array}{l}\text { Participant traverses the mining environment with an emphasis on taking } \\
\text { the least amount of time and travelling the shortest distance possible, } \\
\text { whilst also minimising the amount of physical effort expended in order to } \\
\text { prolong the oxygen supply in their self-rescuer }\end{array}$ \\
\hline Self-rescuer usage & $\begin{array}{l}\text { Participant equips their self-rescuer only when smoke is encountered, } \\
\text { with an emphasis on minimising physical exertion in order to maximise } \\
\text { the duration of oxygen supply if the self-rescuer is equipped }\end{array}$ \\
\hline Escape rise usage & $\begin{array}{l}\text { Participant avoids using escape rises, which are ladders that provide } \\
\text { access between levels of the mine for use when the primary shaft is } \\
\text { obstructed, unless they have no other means of circumventing an obstacle } \\
\text { which is obstructing access to a refuge chamber }\end{array}$ \\
\hline $\begin{array}{l}\text { Encounters with fire and } \\
\text { smoke }\end{array}$ & Participant avoids encounters with smoke and fire where ever possible \\
\hline
\end{tabular}

Performance measures and input logs recorded by FUMES were analysed for evidence of these positive outcomes during participant interaction. The Training Staff Member was also interviewed regarding his observations of participant activity within FUMES for this purpose.

\section{Performance measures}

Performance measures recorded by FUMES identified whether participants reached a refuge chamber, whether they adhered to the ideal route to a refuge chamber, and whether they selected the ideal refuge chamber given the specific circumstances of each problem-solving instance. The ideal route to a refuge chamber was considered to be the most efficient in terms of distance travelled and physical effort exerted within the virtual mine, while the ideal refuge chamber was considered to require the least amount of physical effort to reach from the starting location. Figures 1, 2, and 3 demonstrate participant achievement of these positive outcomes for each problem-solving instance. 


\section{Positive Outcome - Evacuate to refug e chamber}

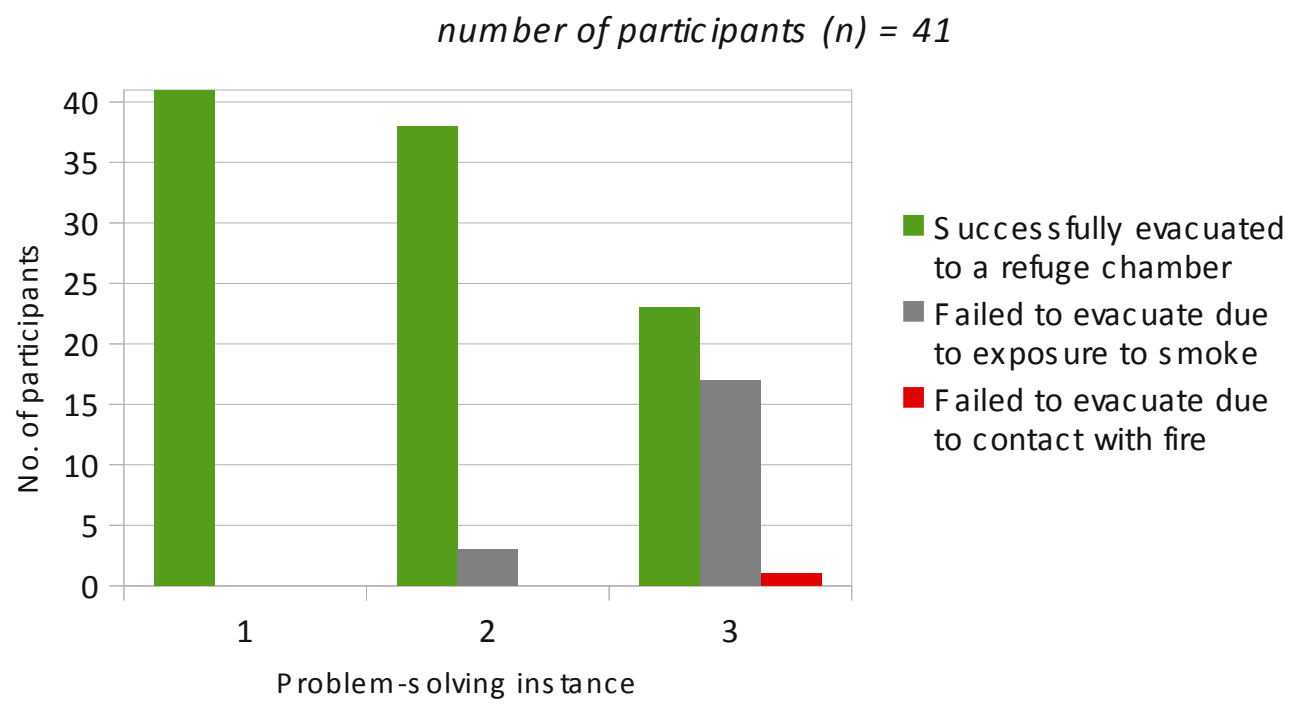

Figure 1. Successful evacuation to a refuge chamber.

\section{Pos itive Outc ome - Ideal route number of participants $(n)=41$}

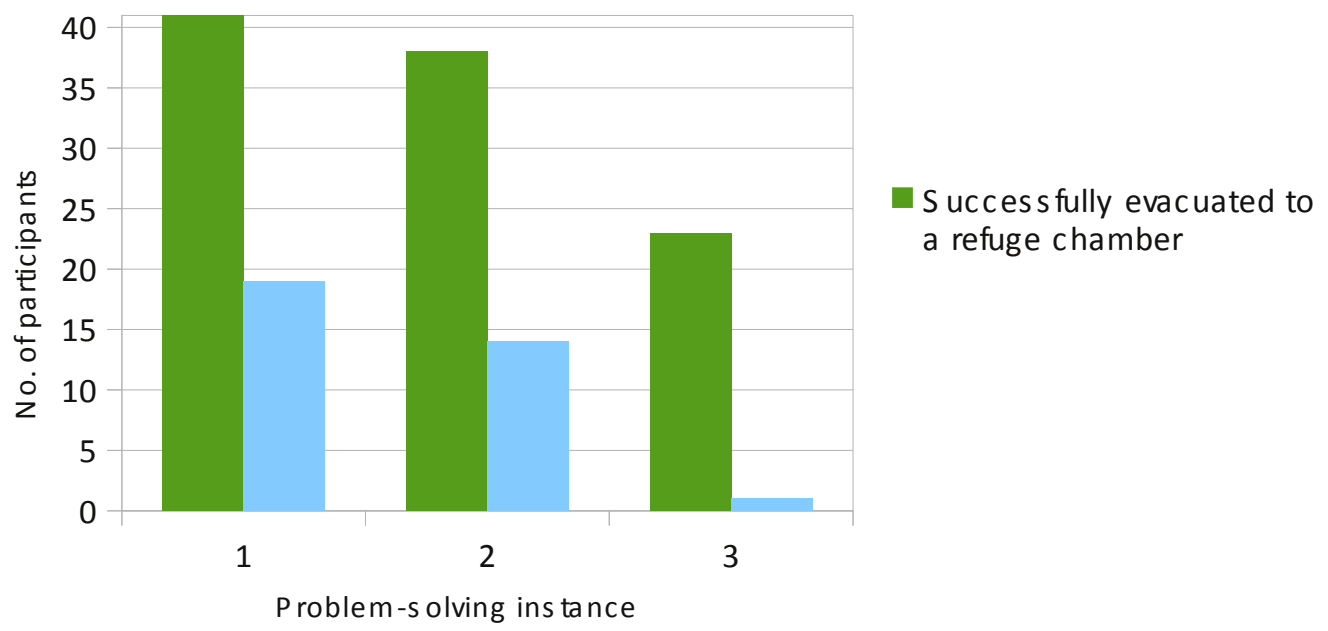

Figure 2. Successful evacuation to a refuge chamber using the ideal route. 


\section{Positive Outc ome - Ideal refug e chamber}

$$
\text { number of partic ipants }(n)=41
$$

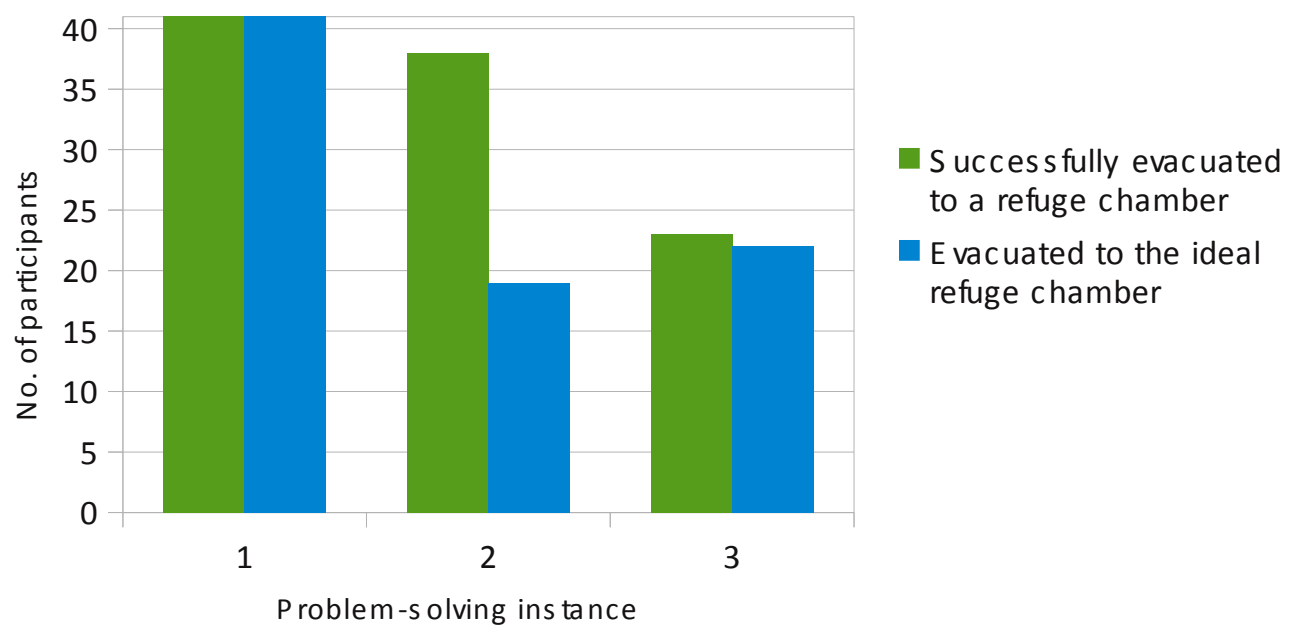

Figure 3. Successful evacuation to the ideal refuge chamber.

Trends in the performance measures suggest that participants achieved positive outcomes within FUMES:

- The overwhelming majority of participants evacuated to a refuge chamber in the first and second problem-solving instances. More than half of the participants evacuated to a refuge chamber in the third problem-solving instance, and;

- Nearly all of the participants who successfully evacuated to a refuge chamber in the first and third problem-solving instances evacuated to the ideal refuge chamber.

The first trend suggests that participants used their existing knowledge of emergency evacuations in the real world mine to evacuate to a refuge chamber in the virtual mine, particularly in the first two problemsolving instances. This implied a contextual similarity between problem-solving activity in FUMES and emergency evacuations in the real world mine.

The second performance trend also indicates the application of existing knowledge to identify the ideal refuge chamber for evacuation during a simulated underground fire emergency in the virtual mine. This demonstrated that participants were aware of the environmental factors to consider, although this was far more prevalent in the first and third problem-solving instances. This anomaly could be attributed to the complexity of the second problem-solving instance, where the starting location made the process of determining the ideal refuge chamber more arbitrary compared to problem-solving instances one and three. Taking this into consideration, the ability of participants to identify the ideal refuge chamber for evacuation suggests that existing knowledge of emergency evacuation procedure within the real world mine was being utilised effectively.

Further trends apparent in the performance measures suggest that participants experienced difficulties achieving positive outcomes consistently:

- $\quad$ Participant performance tended to degrade with each subsequent problem-solving instance. This was particularly evident in the third problem-solving instance, where only slightly more than half of the participants were able to evacuate to a refuge chamber, and;

- Less than half of the participants who evacuated to a refuge chamber in the first and second problem-solving instances utilised the ideal route to get there. Furthermore, of the participants who evacuated to a refuge chamber during the third problem-solving instance, only one utilised the ideal route. 
These trends suggest that participants were not consistently able to apply their existing real world knowledge within FUMES to achieve positive outcomes. However, this can be ascribed to the design of the problem-solving task, and the algorithm used by FUMES to evaluate whether the ideal route had been followed.

Each problem-solving instance was designed to be more ill-structured, complex, and domain specific than the one that preceded it, where the amount of information provided to participants explicitly decreased in turn. The specific circumstances of each problem-solving instance also progressed in difficulty in terms of participants' starting location, proximity to refuge chambers and fire, and the severity and spread of smoke within the virtual mine. Given that structuredness, complexity, and domain specificity are factors which are known to affect problem-solving performance (Herron, 1990; Jonassen, 2000; Smith, 1988), it is reasonable to associate the decline in achievement of positive outcomes evident in Figures 1, 2, and 3 with the design of the problem-solving task.

Due to time constraints during development, the algorithm used to evaluate whether participants had followed ideal routes within FUMES was simplistic and merely compared the sections of the virtual mine that had been traversed with a pre-determined ideal route for each problem-solving instance. While this did provide a basic means to determine whether participants followed the ideal route to a refuge chamber, it did not consider minor variations or deviations. Thus, the data presented in Figure 2 only accounts for those participants whose route to a refuge chamber exactly matched the pre-determined ideal route. Further insight into participants' route through the virtual mine was evidenced via the input logs, as documented in the following section.

Based on the design of the problem-solving task, and the way in which participant's adherence to the ideal route was evaluated within FUMES, the negative trends observed in the performance measures can be accounted for. This indicates that overall, participants achieved positive outcomes relating to successful evacuation to the ideal refuge chamber due to the similarities between problem-solving activity in FUMES and emergency evacuations in the real world mine. This infers the application of existing real world knowledge and the occurrence of learning transfer in accordance with the inverse transfer of training measure.

Input $\log S$

A series of input logs were used to record keystroke and mouse interaction for each participant within FUMES. This allowed participant performance to be replayed to observe and analyse their actions within the virtual mine.

The input logs were examined for evidence of positive outcomes relating to efficiency, self-rescuer usage, escape rise usage, and encounters with smoke and fire within FUMES (Table 1). The behavioural characteristics of participants that were utilised to determine the occurrence of these positive outcomes are listed in Table 3.

Table 3

Behavioural characteristics used to determine positive outcomes in FUMES

\begin{tabular}{|c|c|}
\hline Positive outcome & Relevant behavioural characteristics as observed via input logs \\
\hline Efficiency & $\begin{array}{l}\text { - Speed at which participants moved through the mine (walking or running) } \\
\text { Extent to which participants utilised the most efficient route to a refuge } \\
\text { chamber } \\
\text { - Tendency for participants to travel up or down the decline (primary mine } \\
\text { shaft) } \\
\text { - Extent to which participants demonstrated awareness of where they were } \\
\text { and where they were going within the virtual mine. }\end{array}$ \\
\hline Self-rescuer usage & - Circumstances under which participants would activate their self-rescuers \\
\hline Escape rise usage & $\begin{array}{l}\text { - Circumstances under which participants would use escape rises within the } \\
\text { virtual mine }\end{array}$ \\
\hline $\begin{array}{l}\text { Encounters with fire } \\
\text { and smoke }\end{array}$ & - Participant responses to fire and smoke when encountered \\
\hline
\end{tabular}


Twenty-five input recordings were available for analysis, from which the following trends were observed:

Efficiency

- Participants tended to walk through the virtual mine, although they did run unnecessarily on occasion;

- Participants tended to travel downwards through the mine during the first two problem-solving instances, and upwards through the mine during the third problem-solving instance, consistent with the locations of the ideal refuge chambers for each of these problem-solving instances;

- Participants who appeared disorientated tended to be more likely to deviate from the ideal route to a refuge chamber. Those participants who appeared to be disorientated tended to repeatedly look around the virtual mine to locate visual cues which would provide an indication of the their location, and;

- Participants appeared more likely to suffer from disorientation in the side-shafts, rather than the main decline, where less visual cues were present

Self-rescuer usage

- Participants tended to activate their self-rescuers when they encountered smoke and began coughing, although some activated their self-rescuers upon observing the vehicle fire during the second problem-solving instance, and;

- Participants tended to initially remain within the smoke, still coughing, while equipping their self-rescuers. Some participants did fail to move out of the smoke before overexposure occurred, but most moved out of the smoke after a few seconds to finish equipping their self-rescuers

Escape rise usage

- Participants tended to avoid using escape rises unnecessarily, although they were sometimes used when participants appeared disorientated, especially if this disorientation occurred in within a side-shaft, and;

- Participants made appropriate use of escape rises during the second problem-solving instance to circumvent the vehicle fire that was blocking access to the decline. Very few participants attempted to walk around the vehicle fire

Encounters with fire and smoke

- Participants tended to avoid fire and were generally quick to equip their self-rescuers when smoke was encountered;

- Participants tended to have no hesitation in moving through smoke affected areas once their selfrescuer had been activated, and;

- Smoke, particularly during the third problem-solving instance, appeared to be a leading cause of disorientation.

The trends in the input $\log$ data demonstrate that participants achieved positive outcomes relating to efficiency, self-rescuer usage, escape rise usage, and encounters with smoke and fire. Participants were generally efficient when traversing the virtual mine, although disorientation was shown to affect their ability to use the ideal route to a refuge chamber, and more likely to occur in side-shafts rather than the main decline. Appropriate use was made of escape rises and self-rescuers, although some issues were identified regarding escape rise usage when disorientated, and self-rescuer application when exposed to smoke. Participants tended to avoid contact with fire, but encounters with smoke were more difficult to circumvent and disorientated participants, particularly during the third problem-solving instance. This was consistent with previous analysis which demonstrated that participant performance degraded in response to increasing severity and spread of smoke within the virtual mine with each successive problem-solving instance. 
Training Staff Member observations

The Training Staff Member indicated that participants responded to the auditory and visual cues that signified the occurrence of an emergency evacuation within the virtual mine by immediately attempting to locate a refuge chamber. This implied that participants recognised the context of the problem-solving task based on their existing knowledge of the signals used to declare an emergency evacuation in the real world mine. This demonstrated the achievement of positive outcomes relating to the performance of procedures required during an emergency evacuation.

Further observations suggested that Experienced Participants were able to apply existing knowledge more effectively within FUMES than Novice Participants as a result of greater real world experience within the mining environment. The Training Staff Member noted that Experienced Participants demonstrated a good understanding of their location as they moved through the virtual mine. In contrast, Novice Participants were observed to struggle to maintain locational awareness and required assistance from the Training Staff Member to orientate themselves and locate a refuge chamber.

\section{Assessment of fidelity}

Experienced Participants and the Training Staff Member were consulted to gauge how similar FUMES was to the real world mining environment for the purpose of measuring transfer using the assessment of fidelity method (see Table 1). Experienced Participants were asked to what extent they felt the simulator represented the real world mine during an underground fire scenario. Their responses are summarised in Figures 4 and 5, as follows:

The simulation accurately represented the $\mathrm{C}$ hallenger mining environment

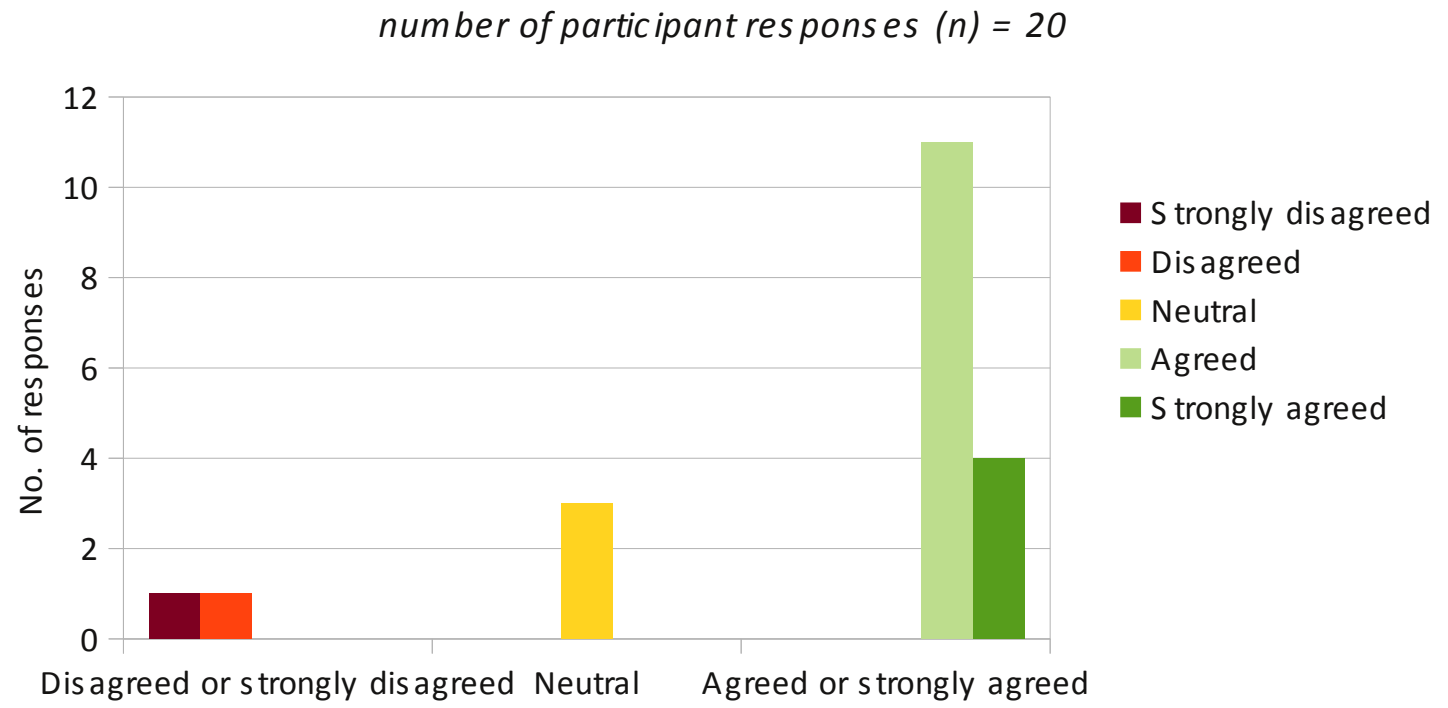

Figure 4. Accuracy with which FUMES represented the real world mining environment. 


\section{The simulation accurately represented the environmental conditions at $\mathrm{C}$ hallenger during a fire underg round}

number of participant respons es $(n)=20$

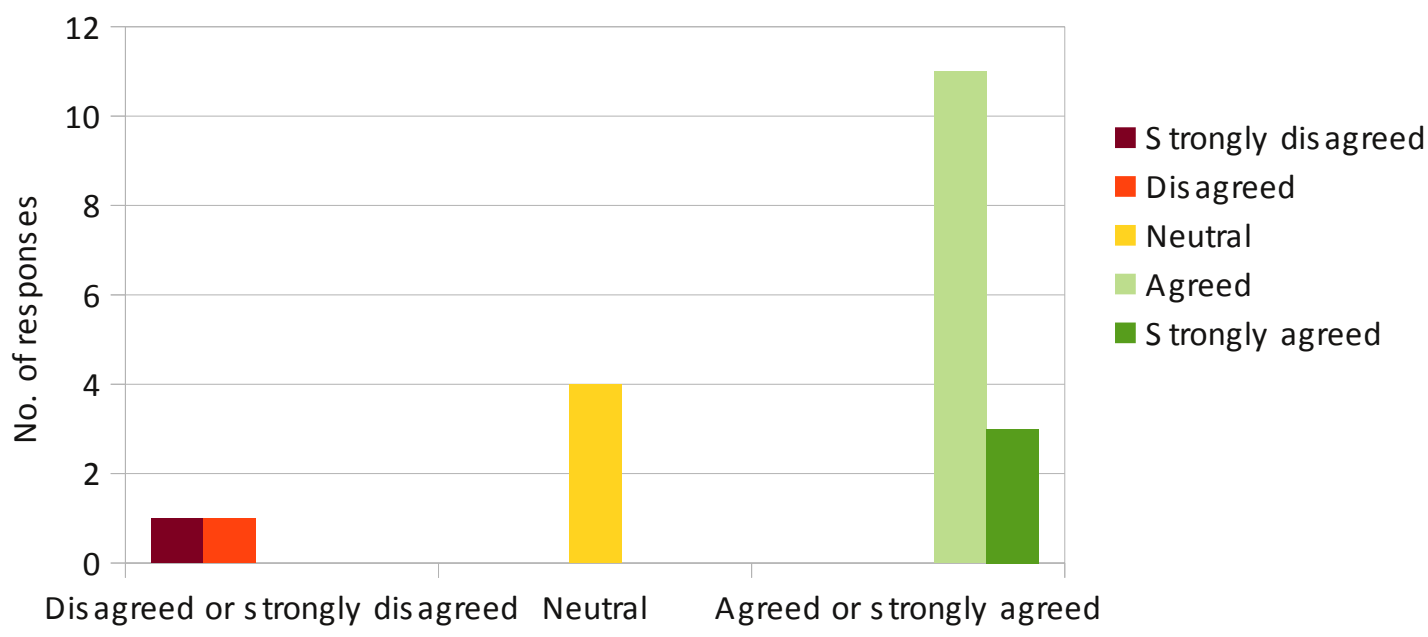

Figure 5. Accuracy with which FUMES represented the environmental conditions of an underground fire scenario in the real world mine.

Ignoring solitary outliers, the questionnaire responses presented in Figures 4 and 5 suggest that FUMES accurately represented the environmental conditions during an underground fire in the real world mine. However, a number of comments provided by Experienced Participants identified specific areas where the accuracy of the representation was deficient.

The most common complaint pertained to a lack of contextual detail within the virtual mining environment. Specifically, FUMES did not depict the servicing infrastructure with sufficient accuracy. Comments indicated that servicing infrastructure was used as a navigational aide within the real world mine and that their absence made it more difficult to orientate and maintain locational awareness within the virtual mining environment. Figures 6 and 7 depict the servicing infrastructure present in the real world mine, and the servicing infrastructure in the virtual mine for comparison.

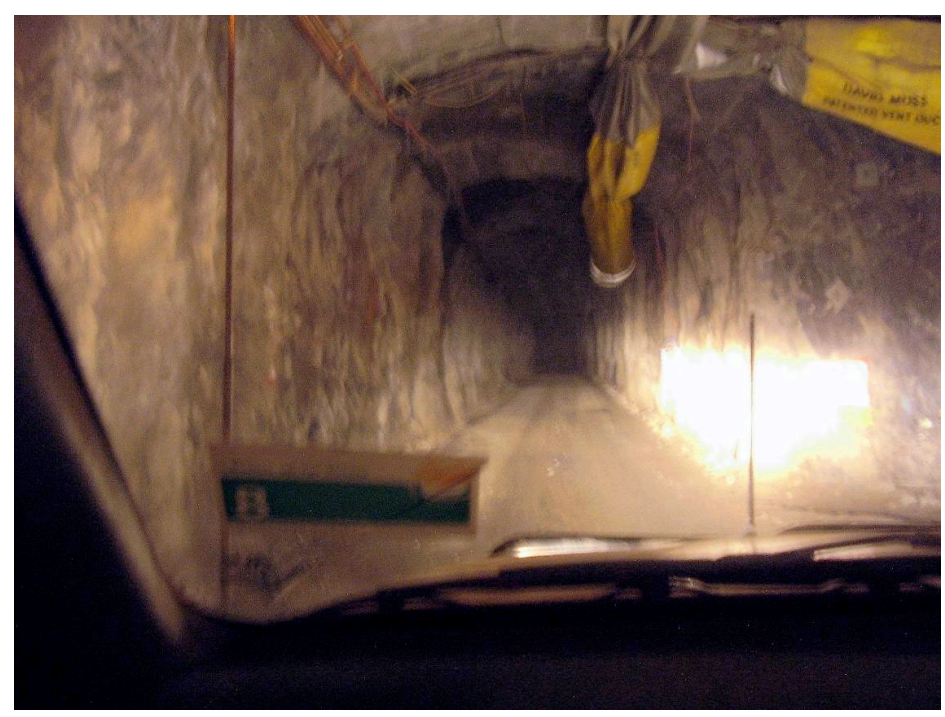

Figure 6. Servicing infrastructure running along the ceiling in the real world mine. 


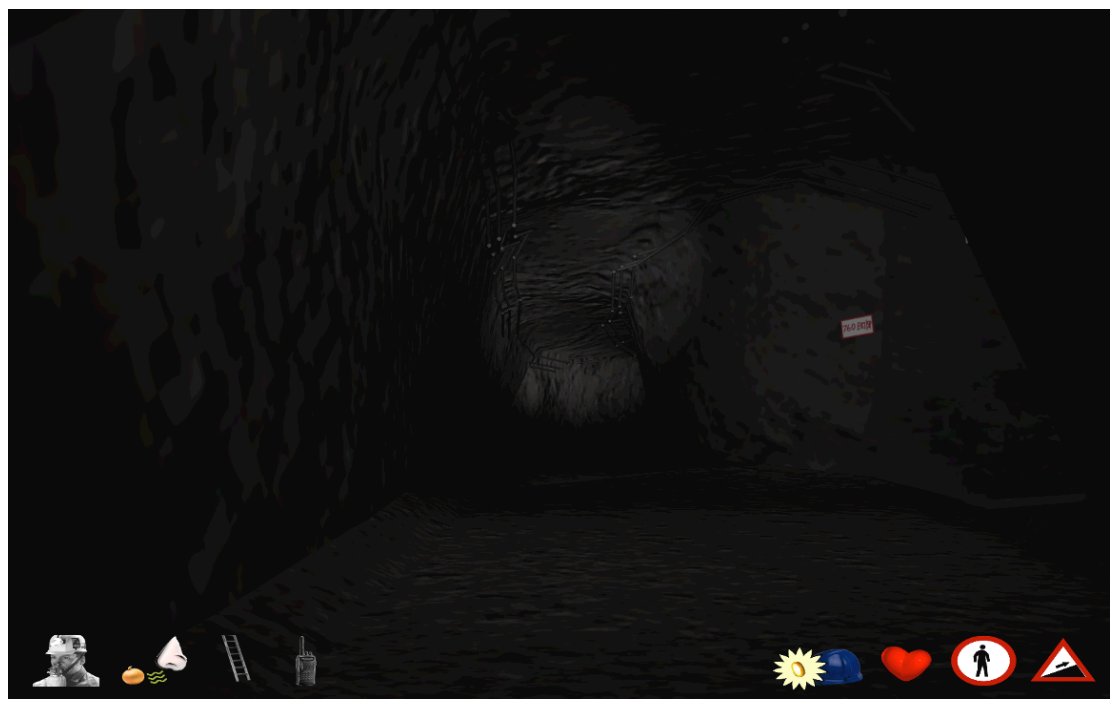

Figure 7. Servicing infrastructure running along the ceiling in the virtual mine.

Four Experienced Participants were also interviewed to assess the physical and functional similarity between the virtual mine and the real world mine. These participants indicated that they identified the virtual mining environment as a representation of the real world mine. Additional comments demonstrated that they recognised familiar areas in the virtual mine, and that the locations of refuge chambers corresponded with those in the real world mine. Functionally, the interviewees indicated that they could move through the virtual mine in a manner that was consistent with the real world counterpart. This suggested that the virtual mine was physically and functionally similar to the real world mine.

However, three out of the four Experienced Participants that were interviewed also acknowledged that servicing infrastructure in the virtual mine was represented inadequately. One participant described the importance of servicing infrastructure in aiding orientation and navigation as follows:

A lot of underground mines have vent bags on the left and services on the right when you come out of drives and levels and onto the decline so in smoky conditions you always knew if you were going in the right direction.

Echoing these sentiments, the Training Staff Member noticed that some participants had problems orientating themselves due to the lack of servicing infrastructure in the virtual mine. The Training Staff Member identified the absence of vent bags, which are large yellow inflatable pipes which run along the ceiling in some sections of an underground mine (Figure 6), as being of particular relevance in this regard:

The vent bag is a good indicator of roughly where they are underground and what is looked for and where to go in the event of an emergency. So that was one of the bigger things that got their orientation a little bit lost.

Thus, while fidelity was sufficient for Experienced Participants to feel familiar with the virtual mining environment, the absence of contextual details, specifically servicing infrastructure, limited their ability to employ methods for orientation and navigation used in the real world mine. This indicated the presence of learning transfer in accordance with the assessment of fidelity measure, where greater fidelity would have resulted in greater transfer.

\section{Operator opinion}

Experienced Participants and Novice Participants were presented with questionnaire prompts designed to gauge their opinion of the training value of FUMES as per the operator opinion method of measuring transfer (see Table 1). Their evaluations were appraised according to: (a) the value of FUMES as a 
training tool; (b) the accuracy with which FUMES represented emergency evacuation procedures during an underground fire; (c) the extent to which FUMES possessed the features necessary for emergency evacuation training, and; (d) the potential impact of FUMES on performance during a real world evacuation at the mine, as summarised in Figure 8.

\section{S ummaris ed operator opinion of FUMES}

$$
\text { number of participant responses }(n)=156
$$

- Experienced $P$ articipants (80 res ponses)

Novice Participants (76 responses)

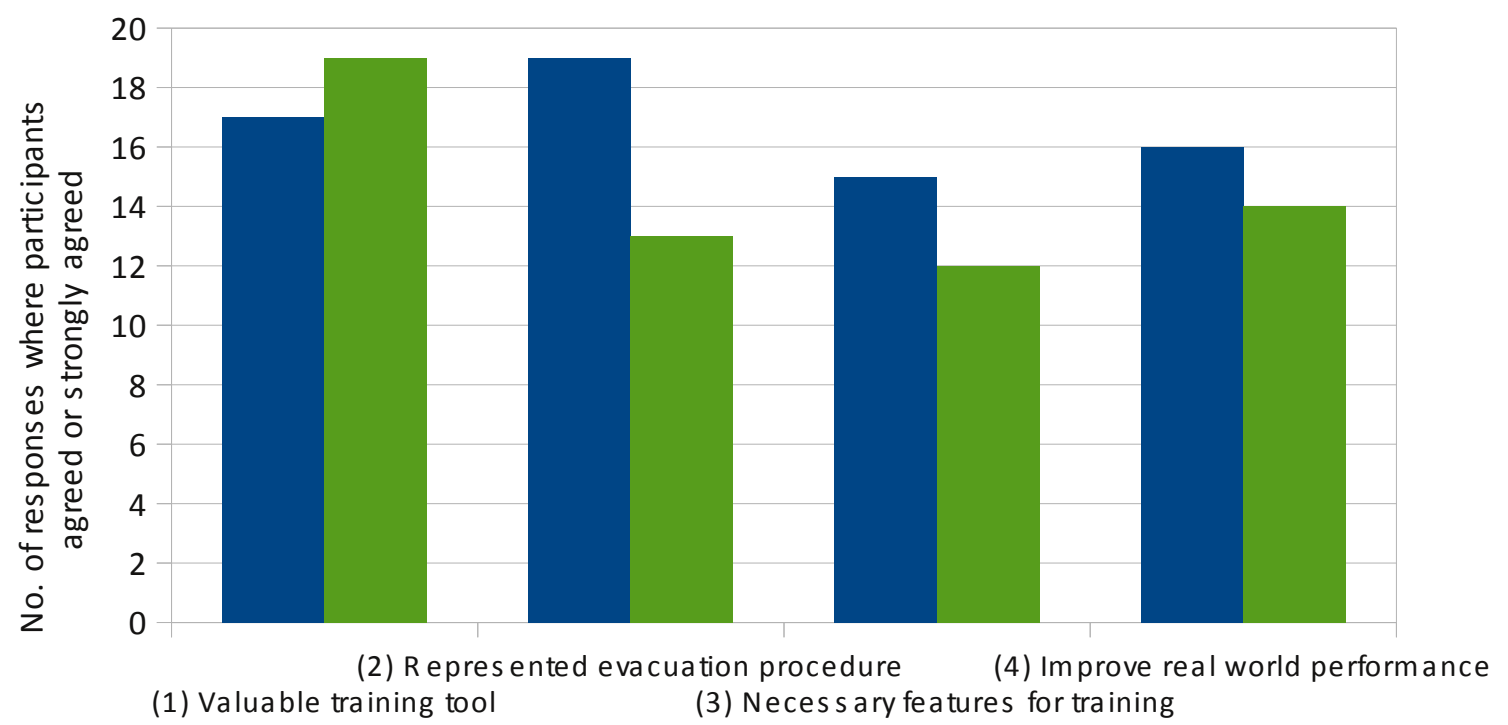

Figure 8. Summarised response of participant opinion of FUMES.

The questionnaire responses demonstrated that participants recognised FUMES as a viable emergency evacuation training platform for personnel at the real world mine (Figure 8). This was evident for both Experienced Participants and Novice Participants, which suggests that FUMES would be suitable for training mining personnel with varying levels of familiarity and experience.

These questionnaire responses were consistent with remarks provided during interviews regarding the value that FUMES would have in training mining personnel to deal with real world emergency evacuations. Responses from the three Novice Participants who were interviewed inferred that personnel with little experience at the real world mine could utilise FUMES to familiarise themselves with emergency evacuation procedures within this environment. Comments emphasised the ability of FUMES to provide an encounter which could be related to in the absence of real world experience, allowing mining personnel to develop an awareness as to what to expect during an emergency evacuation before commencing occupational duties within the real world mine.

Responses from the four Experienced Participants who were interviewed accentuated the experiential nature of FUMES in developing and maintaining knowledge for emergency evacuations in the real world mine. Feedback from these interviewees indicated that mining personnel could use FUMES to sustain their existing knowledge of emergency evacuation procedures within a context of practice that was feasible and accessible beyond the confines and restrictions imposed by operations in the real world mining environment.

The Training Staff Member was also queried about the training value of FUMES given his background in processing personnel through the existing induction training program at the mine. His comments reflected the questionnaire and interview responses provided by Experienced Participants, in that he too saw value in FUMES as an experiential training platform which could be used to refresh and reinforce existing 
knowledge. The Training Staff Member praised FUMES for its ability to promote awareness and further understanding of key equipment such as the self-rescuer, especially for personnel who had long since undertaken induction training and not had further training since. Furthermore, the Training Staff Member also emphasised the ability of FUMES to develop critical thinking and decision making skills during the emergency evacuation process, with the added benefit of allowing personnel to experience and learn from the outcomes of said decisions within the training environment.

\section{Summary for learning transfer}

Data collected during the FUMES implementation was examined for evidence of learning transfer with a view towards determining how problem-solving knowledge and skills could be transferred between a virtual and corresponding real world environment. Three different measures for learning transfer were utilised which did not require performance testing in the real world environment, consisting of the inverse transfer of training method, assessment of fidelity method, and operator opinion method (Lathan , Tracey, Sebrechts, Clawson, \& Higgins, 2002). In this instance, learning transfer was evident in all three of the indirect methods used.

Analysis of the data collected for the inverse transfer of training measure indicated that participants utilised knowledge of emergency evacuations in the real world mine during the problem-solving activity in FUMES. Participants used their existing knowledge to achieve positive outcomes that were consistent with successful emergency evacuations of the real world mine.

The performance measures indicated that participants successfully evacuated to a refuge chamber on the clear majority of occasions and located the ideal refuge chamber consistently during the first and third problem-solving instances. However, the performance measures also demonstrated that participants did not locate the ideal refuge chamber consistently during the second problem-solving instance. This was the result of overly simplistic evaluation of ideal routes by FUMES, which did not take into account minor variations or deviations within the virtual mining environment. The achievement of positive outcomes evidenced via performance measures was also found to degrade with each successive problem-solving instance. This was attributed to the design of the problem-solving task, where each problem-solving instance was more ill-structured, complex, and domain specific than the one that preceded it. This design placed increasing demands on participants in relation to their starting location, proximity to refuge chambers and fire, and the severity and spread of smoke within the virtual mine with each successive problem-solving instance.

Analysis of the input logs showed that participant behaviour tended to correlate with real world emergency evacuation procedures, where participants traversed the virtual mine efficiently, used escape rises and their self-rescuer appropriately, and handled encounters with smoke and fire correctly. Disorientation was found to affect participants' ability to traverse the virtual mine efficiently, with smoke identified as a contributing factor. These findings were consistent with the performance measures, where the decline in achievement of positive outcomes throughout the series of three problem-solving instances corresponded with increasing severity of smoke within the virtual mine.

Observations of participant interaction made by the Training Staff Member indicated that the auditory and visual cues used to signify the occurrence of an emergency evacuation prompted participants to immediately seek out a refuge chamber within the virtual mine. The Training Staff Member also acknowledged that Experienced Participants demonstrated greater locational awareness as they moved through the virtual mine compared to Novice Participants. As a result, Experienced Participants were better able to achieve positive outcomes relating to locating a refuge chamber within the virtual mine. This was attributed to their superior knowledge of, and experience with, the real world mining environment.

Evaluation of the data used for the assessment of fidelity measure suggested that FUMES adequately represented the real world mining environment during an underground fire emergency evacuation scenario. Experienced Participants' acquaintance with the real world mining environment allowed them to feel familiar within the virtual mine, suggesting the presence of learning transfer. However, participant responses demonstrated that a lack of fidelity in the representation of servicing infrastructure had a negative impact on their performance in terms of orientation and navigation within the virtual mine. 
Data analysed for the operator opinion measure implied that participants recognised FUMES as a suitable platform for real world mining personnel to undertake emergency evacuation training. Participants with less experience at the mine emphasised the value of FUMES as a familiarisation tool, while those participants with more experience saw value in FUMES as a training environment in which existing knowledge could be applied experientially in addition to a means by which to refresh existing knowledge. The Training Staff Member also emphasised the value of FUMES as a training platform in which the decision making process during an emergency evacuation scenario could be acted out and learned from.

Collectively, the analysis undertaken using the inverse transfer of training, assessment of fidelity, and operator opinion methods demonstrated the presence of learning transfer. Participants were able to use their knowledge of the real world mining environment and its emergency evacuation protocols to successfully undertake problem-solving tasks within FUMES that were situated in a similar context. This was more evident for Experienced Participants who had a greater wealth of knowledge to draw upon based upon their occupational experience at the real world mining facility.

\section{Value of indirect measures of learning transfer}

Triangulation of the three indirect measures of learning transfer indicated that participants were able to use their existing knowledge of emergency evacuations in the real world mine during problem-solving activity in FUMES. These measures inferred the presence of learning transfer as a result of the contextual similarity between the problem-solving task and the actions, strategies, and decision making processes required to successfully evacuate to a refuge chamber during an emergency in the real world mine. Furthermore, the three indirect measures employed during the study also provided some indication as to the factors in FUMES which encouraged and diminished the transfer of knowledge.

The inverse transfer of training measure demonstrated that the problem-solving task emphasised the same considerations as real world emergency evacuation procedures. Participants recognised that they had to locate a refuge chamber within the virtual mine in order to solve the problem, appreciated the need for efficiency, and understood how to make effective use of the tools available to them in the form of escape rises and their self-rescuer. Transfer was accommodated as a result of the similarities between the real world and virtual mining environments, such that Experienced Participants encountered no difficulties in moving and orientating themselves during problem-solving activity. However, the inverse transfer of training measure also established the need for more sophisticated assessment mechanisms when evaluating whether participants had followed the ideal path to a refuge chamber. Novice Participants' inability to navigate effectively within the virtual mine, despite the provision of a mine layout diagram and assistance from the Training Staff Member, also indicated that they required greater instructional support from FUMES to offset their real world knowledge deficiencies. The degradation in participant performance further suggested that the second and third problem-solving instances needed to be less difficult in order to allow participants to resolve the problem and fully develop their knowledge and understanding.

The assessment of fidelity measure emphasised how environmental knowledge could be transferred between virtual and real world spaces when they embodied consistent spatial characteristics. Despite never having used FUMES prior to the study, Experienced Participants indicated that they immediately felt familiar with the virtual mining environment. However, the assessment of fidelity measure also confirmed that contextual detail and visual fidelity needed to be concentrated in areas of the simulation, which directly related to the resolution of the problem-solving task. The omission of faithfully represented servicing infrastructure had a distinct effect on participant behaviour, whereby they were unable to employ real world strategies for locating a refuge chamber which relied upon these visual cues for navigation.

The operator opinion measure accentuated the value of experiential learning activity in which knowledge is constructed within a context of practice. Participants were encouraged to develop critical thinking and decision making skills in a way that allowed them to experience and learn from the outcomes of their choices. This had a broad appeal to participants who had varying levels of experience with emergency evacuations in the real world mine. Knowledge of emergency evacuation procedures within this environment could be cultivated and reinforced within FUMES. 
This suggests that indirect measures of learning transfer can provide valuable insight into the strengths and weaknesses of the design in terms of their contribution to learning transfer. This information can be used to improve future iterations of the simulation to make it more effective in the development of knowledge for real world application. In this instance, future versions of FUMES could accommodate improvements in terms of greater instructional support for users who lack knowledge of the real world problem domain, and greater visual fidelity in relation to the representation of servicing infrastructure, which aids navigation.

\section{Conclusion}

The primary goal of simulation-based training is to enhance performance in a corresponding real world environment via the transfer of knowledge (Alexander, Brunye, Sidman, \& Weil, 2005; Lathan et al., 2002). As such, it is necessary to verify the extent of this knowledge transfer in order to determine the value of the simulation environment as a platform for real world training. Given the assumption that training in the real world environment is ideal, the aim of achieving optimal transfer lies in making the training context match the performance task as closely as possible (Skinner et al., 2009). As a result, performance testing in the real world environment after using the simulation can provide an indication of the extent to which learning transfer may or may not have occurred.

However, performance testing in the real world environment may not always be possible, necessitating the application of indirect methods for measuring transfer. To this end, methods were utilised which emphasised simulator performance in relation to real world experience, fidelity measures, and the opinions of operators in a study involving the Fires in Underground Mines Evacuation Simulator. These methods for measuring learning transfer (Lathan et al., 2002), consisting of the inverse transfer of training method, the assessment of fidelity method, and the operator opinion method, were found to provide an adequate means by which to determine the presence of learning transfer. The results of this study suggest that real world performance testing may not be the only viable means by which to determine the training and learning value of a 3D simulation environment. Furthermore, indirect methods can also provide valuable insight into the strengths and weaknesses of the simulator design in terms of their contributions to learning transfer which can be used to refine future iterations.

\section{References}

Alexander, A. L., Brunye, T., Sidman, J., \& Weil, S. A. (2005). From gaming to training: A review of studies on fidelity, immersion, presence, and buy-in and their effects on transfer in PC-based simulations and games. DARWARS Training Impact Group. Retrieved from http://www.darwars.com/downloads/DARWARS\%20Paper\%2012205.pdf

Baylis, W. T. (2000). The use of virtual reality in training and education. Logistics Spectrum, 34(4), 2528.

Brown, J. S., Collins, A., \& Duguid, P. (1989). Situated cognition and the culture of learning. Educational Researcher, 18(1), 32-42.

Dalgarno, B., \& Lee, M. J. W. (2010). What are the learning affordances of 3-D virtual environments? British Journal of Educational Technology, 41(1), 10-32.

Depledget, M. H., Stone, R. J., \& Bird, W. J. (2011). Can natural and virtual environments be used to promote improved human health and wellbeing? Environmental Science \& Technology, 45(11), 46604665 .

Dobson, M. W., Pengelly, M., Sime, J. A., Albaladejo, S. A., Garcia, E. V., Gonzales, F., \& Maseda, J. M. (2001). Situated learning with co-operative agent simulations in team training. Computers in Human Behaviour, 17(1), 547-573. 
Garrett, M., \& McMahon, M. (2010). Enhancing the spatial awareness of trainee submariners using 3D game engines as training tools. International Journal of Intelligent Defence Support Systems, 3(3-4), 151-171.

Germanchis, T., Cartwright, W., \& Pettit, C. (2005). Using computer gaming technology to explore human wayfinding and navigation abilities within a built environment. Proceedings of the XXII International Cartographic Conference, A Coruna, Spain, 11-16.

Gopher, D. (2012). Skill training in multimodal virtual environments. Work: A Journal of Prevention, Assessment and Rehabilitation, 41(1), 2284-2287.

Graafland, M., Schraagen, J. M., \& Schijven, M. P. (2012). Systematic review of serious games for medical education and surgical skills training. British Journal of Surgery, 99(10), 1322-1330.

Herron, J. D. (1990). Research in chemical education: Results and directions. In M. Gardner \& J. G. Greeno (Eds.), Toward a scientific practice of science education. Hillsdale, New Jersey: Lawrence Erlbaum.

Jonassen, D. H. (2000). Toward a design theory of problem solving. Educational Technology Research and Development, 48(4), 63-86.

Keh, H., Chang, J., Lin, K., \& Hsu, H. (2005). A 3D situated language exercising system in the WWW environment. International Journal of Distance Education Technologies, 3(3), 65-81.

Lathan, C. E., Tracey, M. R., Sebrechts, M. M., Clawson, D. M., \& Higgins, G. A. (2002). Using virtual environments as training simulators: Measuring transfer. In K. M. Stanney (Ed.), Handbook of virtual environments: Design, implementation, and applications. Malwah, New Jersey: Lawrence Erlbaum.

Li, J., D'Souza, D., \& Du, Y. (2011). Exploring the contribution of virtual worlds to learning in organizations. Human Resource Development Review, 10(3), 264-285.

McHaney, R. (1991). Computer simulation: A practical perspective. San Diego, California: Academic Press.

Merrian, S. B., \& Leahy, B. (2005). Learning transfer: A review of the research in adult education and training. PAACE Journal of Lifelong Learning, 14, 1-24.

Munro, A., Breaux, R., Patrey, J., \& Sheldon, B. (2002). Cognitive aspects of virtual environment design. In K. M. Stanney (Ed.), Handbook of virtual environments: Design, implementation, and applications (pp. 415-434). Malwah, New Jersey: Lawrence Erlbaum.

Petridis, P., Dunwell, I., Panzoli, D., Arnab, S., Protopsaltis, A., Hendrix, M., \& de Freitas, S. (2012). Game Engines Selection Framework for High-Fidelity Serious Applications.

Rose, F. D., Attree, E. A., Brooks, B. M., Parslow, D. M., \& Penn, P. R. (2000). Training in virtual environments: transfer to real world tasks and equivalence to real task training. Ergonomics, 43(4).

Sadowski, W., \& Stanney, K. (2002). Presence in virtual environments. In K. M. Stanney (Ed.), Handbook of virtual environments: Design, implementation, and applications (pp. 791-806). Malwah, New Jersey: Lawrence Erlbaum.

Schroeder, S. A. (2011). Adopting game technology for architectural visualisation (master's thesis). Purdue University, Indiana, USA. Retrieved from http://docs.lib.purdue.edu/cgttheses/6/

Shiratuddin, M. F., \& Thabet, W. (2002). Virtual office walkthrough using a 3D game engine. International Journal of Design Computing, 4. Retrieved from http://researchrepository.murdoch.edu.au/7372/1/Virtual_office_walkthrough.pdf 
Skinner, A., Sebrechts, M., Fidopiastis, C., Berka, C., Vice, J., \& Lathan, C. (2009). Physiological measures of virtual environment training. In P. E. O'Connor \& J. V. Cohn (Eds.), Human performance in high risk environments: Insights, developments, and future directions from military research (pp. 129-149). California: ABC-CLIO.

Smith, M. U. (1988). Toward a unified theory of problem solving: A view from biology. Presented at the Annual Meeting of the American Educational Research Association, New Orleans, LA.

Stone, R. J. (2011). The (human) science of medical virtual learning environments. Philosophical Transactions of the Royal Society of Biological Sciences, 366(1562), 276-285.

Tichon, J., \& Burgess-Limerick, R. (2011). A review of virtual reality as a medium for safety related training in mining. Journal of Health \& Safety Research \& Practice, 3(1), 33-40.

Towne, M. D. (1995). Learning and instruction in simulation environments. Englewood Cliffs, New Jersey: Educational Technology Publications.

Corresponding author: Michael Garrett,m.garrett@ecu.edu.au

Australasian Journal of Educational Technology (C) 2013.

Please cite as: Garrett, M., \& McMahon, M. (2013). Indirect measures of learning transfer between real and virtual environments. Australasian Journal of Educational Technology, 29(6), 806-822. 